\title{
EMPLOYEES' PSYCHOLOGICAL CAPITAL, BURNOUT, AND QUALITY OF WORK-LIFE IN VIETNAMESE ENTERPRISES: MODERATING EFFECTS OF INDIVIDUAL AND ORGANISATIONAL CHARACTERISTICS
}

\author{
Mai Hong Nguyen ${ }^{1 *}$ and Vu Minh Ngo ${ }^{2}$ \\ ${ }^{1}$ Faculty of Business Administration, Van Lang University, 45 Nguyen Khac Nhu Street, \\ Co Giang Ward, District 1, Ho Chi Minh City, Vietnam \\ ${ }^{2}$ School of Banking, University of Economics Ho Chi Minh City, 59C Nguyen Dinh Chieu \\ Street, Ward 6, District 3, Ho Chi Minh City, Vietnam \\ *Corresponding author: mai.nh@vlu.edu.vn
}

Published online: 4 June 2021

To cite this article: Nguyen, M. H., \& Ngo, V. M. (2021). Employees' psychological capital, burnout, and quality of work-life in Vietnamese enterprises: Moderating effects of individual and organisational characteristics. Asian Academy of Management Journal, 26(1), 89-112. https://doi.org/10.21315/aamj2021.26.1.4

To link to this article: https://doi.org/10.21315/aamj2021.26.1.4

\begin{abstract}
Drawing from Positive Organisational Behaviour theory, this research studies the interrelationships of psychological capital, burnout, and quality of work-life with the highlighted moderation of organisational and personal characteristics. The proposed research model on these interrelationships is verified with a sample of 302 employees in both Vietnamese public and private enterprises and the structural equation modeling (SEM) techniques. The results suggest that psychological capital is positively related to the quality of work-life and is negatively related to employees' burnout. In contrast, burnout is negatively related to the quality of work-life. These results suggest the mediating effects of burnout in the relationship between psychological capital and quality of work-life. Additionally, findings show that organisational ownership characteristics moderate the impacts of psychological capital on burnout and those of burnout on employees' quality of work-life as well. However, the moderating effects of demographic characteristics (age and gender) are insignificant. These findings provide several implications for managers
\end{abstract}

(C) Asian Academy of Management and Penerbit Universiti Sains Malaysia, 2021. This work is licensed under the terms of the Creative Commons Attribution (CC BY) (http://creativecommons. org/licenses/by/4.0/). 
to take the advantages of psychological capital in their recruiting, training, and career development programs for employees.

Keywords: positive organisational behaviour, psychological capital, quality of work-life, burnout, public enterprises, private enterprises

\section{INTRODUCTION}

In the 1990s, Vietnam started to build its economy after many years of war and post-war readjustment. During the process of change toward a market-oriented economy and integration into the global economy, nowadays, the highly skilled workforce has gradually risen to be the current most crucial capital for the impressive growth of the Vietnamese economy. Still, retaining employees at their best state is very challenging for Vietnamese employers (Bodewig et al., 2014). In the field of management, there is an imperative demand for exploring the mechanism by which the value of employees and employers can be harmonised and mutually beneficial for both sides of the relationship. Motivating by this demand, scholars have started to pay attention to the employees' wellbeing as the direct results of employees' activities in their workplace and private life. One of the key measures for employees' wellbeing is the quality of work-life. Previous researchers have shown that employees' psychological capital and burnout are advocated to be the critical and direct influencers to this construct (Arandjelovic et al., 2010; Nguyen \& Nguyen, 2012; Nguyen et al., 2014; Akar, 2018).

Due to the extraordinary capacity of positive psychology capital to make people lastingly happier and their life most worth living, the stream of positive psychology research remarkably emerged over the past two decades. Instead of emphasising on human weakness and attempting to eliminate the worst, this research focuses on bringing people better and healthier lives by changing the concentration of psychology from mental illness and dysfunctional behaviour to mental wellness. According to the definition from Seligman et al. (2005), positive psychology is "an umbrella concept for the study of positive emotions, positive character traits, and enabling institutions." There were various applications of positive psychology in diverse disciplines of education, public health, health care, social and human services, economics, political science, neuroscience, and leadership (Donaldson \& Ko, 2010). In terms of management and organisational behaviour, the positive psychological application includes two main research streams focusing on individual and organisational positive effects in recent years: positive organisational scholarship (POS) and positive organisational behaviour (POB) and its derivative psychological capital, which is described as an individual's psychological state of development (Luthans et al., 2015). However, there is little consensus about the 
interrelationships between psychological capital, burnout, and quality of worklife, especially in developing countries. This study focused on the individual-level of the POB approach to analyse the interrelationships of psychological capital, burnout, and quality of work-life of employees in Vietnamese enterprises.

Notably, organisational and individual distinct characteristics are almost ignored when investigating factors that affect employees' quality of work-life. Vietnam is one of the countries with the ratio between men and women in the labour force relatively were in balance over the past 10 years (Vietnam General Statistics Office, 2019). From the fact that the economy was mainly public enterprises, according to "The White Book on Vietnamese Businesses 2019" (Vietnam General Statistics Office, 2019), the private sector is generating approximately $42 \%$ of Vietnam GDP, approximately $30 \%$ of the state budget, and attracting about $85 \%$ of the national workforce. That means for every 100 employees, about 85 people work in private companies. Therefore, gaining in-depth knowledge of these differences is extremely vital for business development in Vietnam and other countries with similar environments such as China or India. This study would benefit organisations in designing appropriate development for employees and will allow them to recruit qualified people based not only on their professional skills but also their psychological traits. All of this could result in a happier and healthier workforce leading to a more prosperous and profitable organisation.

\section{LITERATURE REVIEW}

\section{Psychological Capital}

Psychological capital is defined as:

An individual's positive psychological state of development that is characterized by (1) having confidence (self efficacy) to take on and put in the necessary effort to succeed at challenging tasks; (2) making a positive attribution (optimism) about succeeding now and in the future; (3) persevering toward goals and, when necessary, redirecting paths to goals (hope) in order to succeed; and (4) when beset by problems and adversity, sustaining and bouncing back and even beyond (resiliency) to attain success (Luthans et al., 2007, p. 3).

In other words, as a higher-order construct, psychological capital not only answered the question "Who are you?" but also defined the best person you can develop into (Luthans et al., 2007). The significant impact of psychological capital on workplace performance in both four constructs (hope, optimism, efficacy, and resilience) and 
the general integration psychological capital has been revealed in previous studies (Luthans et al., 2005; Youssef \& Luthans, 2007), leading to its critical impact on organisational performance enhancement and sustainable competitive advantage.

Snyder et al. (1991) described "hope" as a "positive motivational state that is based on an interactively derived sense of successful (1) agency (goal-directed energy) and (2) pathways (planning to meet goals)" (p. 287). Hope indicates "the belief that one can find pathways to desired goals and become motivated to use those pathways" (Snyder et al., 2002, p. 257). This psychological source progressively contributes hope that the objective will be achieved. Hopeful employees express the remarkable ability to develop numerous pathways to attain their goals. The second positive construct is "optimism". It was characterised by Carver and Scheier (2002) that "optimists are people who expect good things to happen to them; pessimists are people who expect bad things to happen to them" (p. 231). This explanation describes the expectancy framework used to distinguish optimistic people and pessimistic people in an organisation. Regardless of personal ability, optimistic staff members are people who have positive expectations of results for themselves in working environments. They are people who have forward-looking beliefs regardless of past issues or setbacks.

"Efficacy" is people's determination in their capacity to accomplish a specific goal in a specific condition. It is also defined as people's trust in their abilities to generate designated levels of performance that influence their lives and decide how people feel, think, stimulate themselves, and behave (Judge et al., 2007). Staffs with high efficaciousness are described as tenacious pursuit and persistent efforts toward achievement and are directed by trusts in their own successes. Finally, Luthans (2002) defined "resilience" as a "positive psychological capacity to rebound, to bounce back from adversity, uncertainty, conflict, failure, or even positive change, progress and increased responsibility" (p. 702). Applying resilience to the professional level in a firm, workers have the ability to adjust to extremely challenging circumstances positively.

The characteristic of plastic and malleable to change and development in organisations or "state-like" is one of the most vital traits of psychological capital. State-like psychological capacities are more likely to adapt over time and are more explicit to certain situations or tasks whilst trait-like characteristics such as personality or core self-evaluations are more likely to be solid over time and are not specific to any task or situation (Peterson et al., 2011). More importantly, psychological capital can be changed and developed through short training interventions (Dello Russo \& Stoykova, 2015; Demerouti et al., 2011; Luthans \& Youssef-Morgan, 2017). Thus, organisations should pay attention to effectively 
improve their human resource management in increasing positivity, alleviating negativity, and enhancing well-being due to these characteristics of psychological capital. Based on these profound benefits, studies investigating the outcome of psychological capital on employees' performances have emerged recently. In a notable quantitative systematic meta-analysis of psychological capital on employee attitudes, behaviours, and performance which included 51 independent samples (representing a total number of 12,567 employees), the outcome provided vitally predicted positive connections between psychological capital and desirable employee attitudes (job satisfaction, organisational commitment, and psychological well-being), desirable employee behaviours (citizenship), and multiple measures of performance (self, supervisor evaluations, and objective) (Avey et al., 2011).

\section{Burnout}

Maslach et al. (1996) used the term burnout as a syndrome of three dimensions emotional exhaustion, cynicism or depersonalisation, and reduced professional accomplishment. Firstly, emotional exhaustion is caused when staff members feel severe emotional fatigue and diminished or no ambition to employment. Exhaustion is the central quality of burnout and the most obvious manifestation of this complex syndrome (Maslach et al., 2001). In the three aspects of burnout, exhaustion is the most widely reported and the most thoroughly analysed but it is insufficient (Maslach, 2003). Secondly, cynicism is created when employees get away from work and indicate an indifferent and callous attitude at firms. Lastly, reduced personal accomplishment is attained when people feel a lack of competence and successful work accomplishment. Moreover, it is crucial to notice the process of burnout in time. In the first stage, exhaustion may appear in coping with high demand from the workload and stress, following by the symptom of cynism and leading to the last stage when employees are consumed to feel lack of efficacy (Maslach et al., 2001).

It is theoretically safe to assume the negative relations between the two constructs (Luo \& Hao, 2010; Luthans et al., 2004). For instance, one of the mentioned dimensions of burnout - cynicism - has been described as an outcome of psychological capital in the meta-analysis of Avey and his colleagues (2011). Luo and Hao (2010) discovered proof for the preventative impact of psychological capital on job burnout through organisational commitments using Chinese nurses as attendants. Using another sample of 1,496 Chinese nurses, Ding et al. (2015) claimed more explicit evidence that psychological capital had a direct negative effect on all dimensions of burnout and an indirect effect through coping style as a mediator. The same outcomes are also confirmed by a sample of 357 university 
lecturers in Beijing (Pu et al., 2017). Notably, psychological capital can profoundly influence the process of job burnout development by productively decreasing the extent of burnout (Luthans et al., 2004). Consequently, the following hypothesis was proposed:

H1: Psychological capital is negatively associated with burnout.

\section{Quality of Work-Life}

Quality of work-life is defined as an employee's satisfaction with a variety of needs through resources, activities, and outcomes stemming from participation in the workplace (Sirgy et al., 2001). More recently, Marta et al. (2013) proposed a way to conceptualise quality of work-life, based on the Maslow's hierarchy of needs. The authors operationalised quality of work-life as employee satisfaction of seven sets of human developmental needs: (1) health and safety needs, (2) economic and family needs, (3) social needs, (4) esteem needs, (5) actualisation needs, (6) knowledge needs, and (7) esthetic needs (Marta et al., 2013). By this approach, quality of work-life was conceptualised in terms of need satisfaction stemming from an interaction of employee's needs (survival, social, ego, and selfactualisation needs) and those organisational resources relevant for meeting them. Besides the satisfaction approach, the spillover approach of quality of work-life indicated that when employees satisfy in one area of life, they tend to satisfy in other areas (Sirgy et al., 2001).

In general, a large body of evidence indicates that adverse reactions in workplaces may come out from burnout syndrome such as job dissatisfaction, lower productivity and quality of work, and reduced commitment. Anagnostopoulos and Niakas (2010) analysed 487 Greek nurses working in the National Health Care System and indicated that burnout might not only negatively impact the quality of life of health-care providers but also may influence short sick leaves. Moreover, burnout not only influences people who stay on the job but also causes them to want to quit their job. Take cynicism as an example, scholars showed that it is one of the vital aspects to anticipate turnover and it is also a mediator between bullied in the workplace and intention to leave the job. Karisalmi (1999) examined the relationship of burnout and the quality of work-life in retail trade and metal industry which revealed that six dimensions of the quality of work-life (organisation of work, work of superior, conflicts, job control, job demands, and monotonous job) had different impacts on job burnout in both the retail trade and in the metal industry. Among 314 volunteer teachers in Turkey, their perceptions of quality of work-life were negatively associated with burnout and school alienation 
(Akar, 2018). Based on the limited studies about the relationship between burnout and quality of work-life, the following hypothesis was proposed:

H2: Burnout is negatively associated with quality of work-life.

Previous research found that psychological capital is positively related to employees' psychological health and job satisfaction (Luthans et al., 2005). Studies also demonstrated that these four components (hope, optimism, efficacy, and resilience) of psychological capital have positive relationships with performance, happiness, well-being, and satisfaction of employees. As an analogy, efficacy has been discovered to have a positive effect on performance (Stajkovic \& Luthans, 1998); employee's optimism is linked to their performance, satisfaction, and happiness (Youssef \& Luthans, 2007); hope is connected with employees' performance, satisfaction, happiness, and retention (Youssef \& Luthans, 2007), and resilience has a positive relationship with employee performance and happiness and satisfaction (Youssef \& Luthans, 2007). Essentially, the positive relationship of psychological capital and quality of work-life has been shown in a study of 364 marketers in the emerging economy like Vietnam (Nguyen \& Nguyen, 2012; Nguyen et al., Minh, 2014). A study of Gupta et al. (2019) confirmed the role of psychological capital as a mediator between work engagement and five components of quality of worklife. Compare to its components, psychological capital overall is a better predictor of staff performance (Luthans et al., 2007). Hence, this study concentrated on the anticipating power of psychological capital as an overall construct rather than investigating its individual parts' effects. Thus, the third hypothesis was proposed as follows:

H3: Psychological capital is positively associated with quality of work-life.

\section{Moderating Effects of Organisational Ownership Structure (State-Owned and Private-Owned)}

Moderating impacts of organisation ownership structure on the psychological capital-burnout and psychological capital-quality of work-life relationships were suggested in this paper for the sake of relatively few historical studies in the area. A research conducted by Shahnawaz and Jafri (2009) highlighted the role of organisational context in psychological capital research. It showed that employees in public organisations have more self-efficacy but less optimism and hope to private sectors. Another research, however, also stated that psychological antecedents and consequences on organisational commitment could be different in these two kinds of organisations (Lyons et al., 2006). State-like characteristics of psychological capital can be one reason for this difference due to its elastic 
aspect in organisational type. Regarding to burnout, outcomes from a sample of 281 teachers in Portugal acknowledge higher levels of emotional exhaustion and cynicism in public than in private schools. In other words, "positive" aspects of burnout are likely to be obvious in private schools while "negative" aspects are more apparent in public schools (Ferreira \& Martinez, 2012). Nevertheless, based on a nationwide survey in Taiwan, Yeh et al. (2018) argued that two types of burnout which are personal burnout and work-related burnout are both higher in private companies. Given the above, it occurs that the context of organisation between state-owned and private-owned enterprises has considerable effects on the relationships between psychological capital with quality of work-life and burnout. However, there were various different arguments in this concern. Therefore, the following hypotheses were proposed:

H4a: Organisational ownership structures (state-owned and private-owned) moderate the relationship between psychological capital and burnout.

H4b: Organisational ownership structures (state-owned and private-owned) moderate the relationship between psychological capital and quality of work-life.

\section{Moderating Effects of Individual Demographic Characteristics}

Besides the impacts of the organisational characteristics, the impacts of individual characteristics (age and gender) on the proposed relationships in the research model were also investigated in this study. To our knowledge, there are relatively few studies in the area of connection between demographic variables and psychological capital as a core construct (Avey et al., 2010). Age and psychological capital were significantly linked in a negative direction (Avey et al., 2010). Even though no researchers have predicted male-female differences in psychological capital, related research findings offer at least suggestive evidence that there may be crucial gender differences. For example, previous papers present male-female differences in levels of resilience that men are more resilient than women (Bonanno, 2004). If women consistently vary from men on some components of psychological capital, there may be differences in the factor structure by gender. Particularly, women are likely to be more emotionally exhausted than men, but men are likely to be more depersonalised than women (Purvanova \& Muros, 2010). At management level, a recent study of the Canadian Mental Health Association (2019) revealed a large propotion (36\%) of 476 entrepreneurs experienced burnout, more particularly, this outcomes have significantly impacted by gender, $41 \%$ of female entrepreneurs witnessed burnout symptoms compare to only $29 \%$ those of male. On the contrary, the covariance of the effects of gender and job level on burnout components, 
while controlling for tenure, indicated insignificant differences between men and women in the amount of emotional exhaustion, depersonalisation, or personal accomplishment (Pretty et al., 1992). Therefore, the following hypotheses were proposed:

H5a: Individual demographic characteristics (age and gender) moderate the relationship between psychological capital and burnout.

H5b: Individual demographic characteristics (age and gender) moderate the relationship between psychological capital and quality of work-life.

Based on the above analyses, a conceptual model for this study was created, clarifying the roles of psychological capital in burnout and quality of work-life as presented in Figure 1.

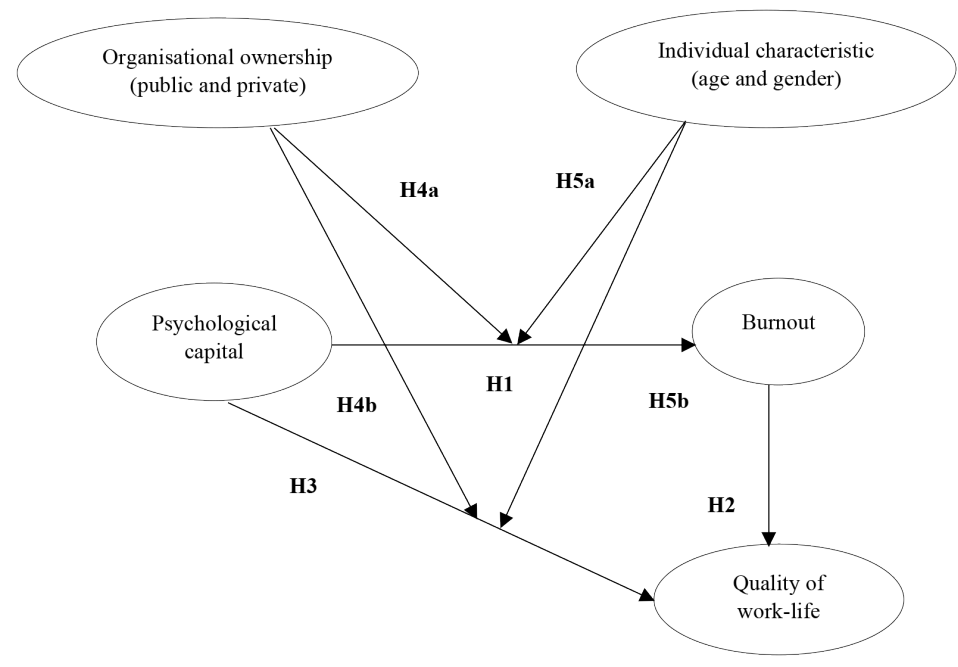

Figure 1. Conceptual model

\section{METHODOLOGY}

The research process of this study consisted of two stages, a qualitative pilot study for clarifying measurement scale and a survey for collecting data used in a quantitative study of proposed relationships between the constructs. The study was mainly conducted in Ho Chi Minh City, the main business centre of Vietnam. First, a series of in-depth interviews with five employees working for five different organisations was conducted in Ho Chi Minh City in March 2019 to validate the measurement scale. This phase is significant to make the measures of constructs 
appropriate for the context of this study even though they are available in previous literature.

Moving to the next step, the purposive sample of this study includes 302 employees concentrate on large businesses $(64.2 \%)$ due to the reason that large organisations normally pay more attention and resources to human resource management as their fundamental strategic part, which is an important factor for effectively develop psychological capital in the workplace (Luthans \& Youssef, 2017). Respondents are 142 employees working in public enterprises (47\%) and 160 employees working in private enterprises (53\%) with diverse specialisation. Questionnaires were used as the instruments for undertaking the survey and were distributed to respondents using both online and offline methods. In each organisation, there was one person who took the role of survey assistant to respond to any enquiries and to collect the results in time in both methods. A one-day training was organised for these assistants one week prior to the main survey to confirm that they clearly understood the method and content of the survey. A total of 115 questionnaires were released to employees of eight firms in Ho Chi Minh City through Google Form to their official emails in April 2019 and there were 102 feedbacks received after two months. Meanwhile, a total of 230 questionnaires were sent to employees of seven firms in Ho Chi Minh City through printed questionnaires with 200 feedbacks after two months. Overall, 302 valid answers could be used in this study at a response rate of $87.5 \%$.

The sample consisted of $63.9 \%$ of females and $36.1 \%$ of males. The ages of the respondents varied from 18 to 55 years (mean $=33.4 ; \mathrm{SD}=9.6$ ). With regard to education, $95.7 \%$ of the participants had tertiary qualifications. Considering work experience, $68.1 \%$ of them worked more than 3 years with $31.1 \%$ had experience for over 10 years. The distribution of respondents' position level was the junior staff $(29.8 \%)$, senior staff $(52.3 \%)$, manager (11.9\%), and others $(4.3 \%)$.

\section{DATA ANALYSIS AND RESULTS}

\section{Measurement}

Psychological capital, quality of work-life, and burnout were investigated in this study, and all of the constructs are second-order constructs. The measurement scale of these constructs is adapted from previous research. The most widely recognised psychological capital questionnaire, PCQ-24 has been used in this study due to its prevalence in psychological capital research (Avey et al., 2011; Newman et al., 2014). Hope construct was measured by four items acquired from Snyder et al. 
(2002). Note that state hope is utilised in this study (Snyder et al., 2002). Optimism construct was measured by three items borrowed from Carver and Scheier (2002). The resilience construct was measured by four items, following Block and Kremen (1996). To measure self-efficacy, we used four items, borrowed from Parker (1998). Nine items focusing on need satisfaction of staff developed by Sirgy et al. (2001) was used to measure the quality of work-life. This scale contained three items which are survival needs, belonging needs, and knowledge needs. Seven-pointLikert scale, anchored by 1 (strongly disagree) and 7 (strongly agree) was used for psychological capital and quality of work-life in this study. Finally, job burnout contained three dimensions which are exhaustion, cynicism, and professional efficacy - mainly based on Maslach Burnout Inventory-General Survey (Maslach et al., 1996). As suggested by Schutte et al. (2000), one item ("When I am at work or I am working I do not want to be bothered") was eliminated because it was shown to be ambivalent and thus unsound. Seven-point Frequency rating scale, ranging from 1 (never) to 7 (always) was used to collect the responses of burnout.

\section{Common Method Bias}

It is the inherited problem with self-administrated data collection techniques that they can contain common factors such as the instrument or social desirability, making the responses biased (Podsakoff et al., 2003). This common method bias happens when there is a hidden factor that accounts for a significant portion of variances of the responses rather than the factors that they intend to measure. This study takes the approach form Podsakoff et al. (2003) to include a common-method factor that accounts for all the indicators in the model to measure the strength of the common bias from hidden sources. The results showed that the average variance explained by the researched constructs in the original model was 0.81 , while the average variance explained by the added common-method factor was 0.02 . The ratio was about 40.5:1. Furthermore, most of the common-method factor loadings were not statistically significant. Given the small magnitude and insignificant variance explained by the common-method factor, the common method bias was unlikely to be the primary concern for this study.

\section{Measurement Model}

The confirmatory factor analysis (CFA) is executed with the measurement model in this state to measure the reliability and validity of measurement scales used in this study. From the result of CFA, all the composite reliability coefficients were larger than 0.70 and all the average variance extracted (AVE) measures were also above 0.05 . It means that the latent constructs account for more than $50 \%$ of the variances of the indicators. Thus, the measurement scales for all the factors in this 
study are reliable. We also assessed the convergent validity, the level of agreement between the items intended to measure an underlying construct. The average loading for each block of items was relatively high (from 0.7 to 0.9 ), and the range in which the loadings in each block of factors vary was narrow. Furthermore, the $t$-values indicate that all the loadings were significant. These results indicated that all the items in each block help in estimating the underlying factors. For assessing the discriminant validity, the criterion of Fornell and Larcker (1981) is followed, which stated that if the AVE is larger than the squared correlation between factors, the discriminant validity can be achieved. The results from Table 1 proved that this criterion is satisfied by most of the constructs (except for professional efficacy). As a result, discriminant validity for our model is at an acceptable level for further analysis.

Table 1

Construct correlation and square root of AVE

\begin{tabular}{|c|c|c|c|c|c|c|c|c|c|c|c|}
\hline & Constructs & 1 & 2 & 3 & 4 & 5 & 6 & 7 & 8 & 9 & 10 \\
\hline 1 & Hope & 0.583 & & & & & & & & & \\
\hline 2 & Optimism & 0.389 & 0.627 & & & & & & & & \\
\hline 3 & Resiliency & 0.405 & 0.377 & 0.595 & & & & & & & \\
\hline 4 & $\begin{array}{l}\text { Self- } \\
\text { efficacy }\end{array}$ & 0.312 & 0.453 & 0.476 & 0.646 & & & & & & \\
\hline 5 & $\begin{array}{l}\text { Survival } \\
\text { needs }\end{array}$ & 0.367 & 0.498 & 0.392 & 0.409 & 0.733 & & & & & \\
\hline 6 & $\begin{array}{l}\text { Belonging } \\
\text { needs }\end{array}$ & 0.352 & 0.323 & 0.378 & 0.423 & 0.503 & 0.596 & & & & \\
\hline 7 & $\begin{array}{l}\text { Knowledge } \\
\text { needs }\end{array}$ & 0.349 & 0.401 & 0.423 & 0.415 & 0.655 & 0.504 & 0.730 & & & \\
\hline 8 & Exhaustion & 0.213 & 0.187 & 0.175 & 0.167 & 0.504 & 0.453 & 0.532 & 0.618 & & \\
\hline 9 & Cynicism & 0.201 & 0.231 & 0.194 & 0.192 & 0.654 & 0.602 & 0.556 & 0.630 & 0.689 & \\
\hline 10 & Efficacy & 0.233 & 0.179 & 0.255 & 0.242 & 0.513 & 0.497 & 0.545 & 0.607 & 0.554 & 0.561 \\
\hline
\end{tabular}

\section{CFA Model for Second-Order Constructs}

As discussed earlier, psychological capital, burnout, and quality of work-life are second-order latent factors measured by their subfactors. Thus, the CFA model is constructed for each of the second-order constructs to assess whether they are valid and reliable when measured by their subfactors. The model fit is measured through several types of fit indexes (absolute/predictive fit, comparative fit, and other fit indexes) presented in Table 2. From the results in Table 2, the three models fit well with the data when most of the fit indexes fall in their acceptable ranges. 
First, psychological capital was a second-order construct comprising four components: hope, optimism, resilience, and self-efficacy. The CFA results indicate that the measurement model of psychological capital received an acceptable fit: $\chi^{2}[28]=125.450(p=0.000), \mathrm{GFI}=0.934, \mathrm{IFI}=0.951, \mathrm{CFI}=0.950$, and RMSEA $=0.071$. Second, burnout was a second-order construct comprising three components: exhaustion, cynicism, and professional efficacy. The CFA results indicate that the measurement model of burnout received an acceptable fit: $\chi^{2}$ [31] $=250.355(p=0.000), \mathrm{GFI}=0.887, \mathrm{IFI}=0.932, \mathrm{CFI}=0.932$, and RMSEA $=$ 0.089 . Finally, quality of work-life was a second-order construct comprising three components: survival needs, belonging needs, and knowledge needs. The CFA results indicate that the measurement model of quality of work-life received an acceptable fit: $\chi^{2}[15]=9.091(p=0.000), \mathrm{GFI}=0.990, \mathrm{IFI}=0.996, \mathrm{CFI}=0.996$, and RMSEA $=0.041$. Moreover, all CFA factor loadings from the three models were equal to or greater than $0.73(p<0.001)$. These findings indicate that the scales measuring the components of psychological capital satisfied the requirement for unidimensionality and within-method convergent validity. Further, all factor correlations were significantly below unity $(p<0.001)$, supporting the withinconstruct discriminant validity between the components of psychological capital (Steenkamp \& Van Trijp, 1991).

Table 2

Fit indexes of the research model

\begin{tabular}{lccc}
\hline Indexes & Psychological capital & Burnout & Quality of work-life \\
\hline $\begin{array}{l}\text { Absolute/predictive fit } \\
\text { Chi-square }\left(\chi^{2}\right)\end{array}$ & $\begin{array}{c}125.45 \\
(p=0.000)\end{array}$ & $\begin{array}{c}250.35 \\
(p=0.000)\end{array}$ & $\begin{array}{c}9.091 \\
(p=0.000)\end{array}$ \\
$\begin{array}{l}\text { Comparative fit } \\
\quad \text { Incremental fit index (IFI) }\end{array}$ & 0.951 & 0.932 & 0.996 \\
$\quad$ Comparative fit index (CFI) & 0.950 & 0.932 & 0.996 \\
$\begin{array}{l}\text { Other } \\
\text { Goodness-of-fit index (GFI) }\end{array}$ & 0.934 & 0.887 & 0.990 \\
$\begin{array}{l}\text { Root mean square error of } \\
\text { approximation (RMSEA) }\end{array}$ & 0.071 & 0.089 & 0.041 \\
\hline
\end{tabular}

\section{Structural Model}

The scores imputed from the three CFA models for the subfactors are used as the indicator data for the second-order factors in the structural model, presenting the relationships between psychological capital, burnout, and quality of work-life 
(Figure 2). The structural model also received an acceptable fit: $\chi^{2}[64]=570.534$ $(p=0.000), \mathrm{GFI}=0.871, \mathrm{CFI}=0.932$, and $\mathrm{RMSEA}=0.057$.

The structural equation modeling (SEM) results, as presented in Figure 2 and Table 3, showed that the data analysis support the proposed hypotheses H1, H2, and H3. A closer examination of the structural paths indicates that consistent with H1, psychological capital had a negative effect on burnout $(\beta=-0.479, p<0.001)$. $\mathrm{H} 2$ proposed a negative relationship between burnout and quality of work-life. This hypothesis also received support $(\beta=-0.274, p<0.001)$ from the data. H3 proposed a positive effect of psychological capital on quality of work-life. This effect was supported $(\beta=0.765, p<0.001)$.

Table 3

Unstandardised structural paths in the research model

\begin{tabular}{llccc}
\hline Hypothesis & Structural path & Estimate & Std. error & $t$-stat \\
\hline H1 & Psychological capital $\rightarrow$ Burnout & $-0.479^{* * *}$ & 0.107 & -4.491 \\
H2 & Burnout $\rightarrow$ QWL & $-0.274^{* * *}$ & 0.070 & -3.933 \\
H3 & Psychological capital $\rightarrow$ QWL & $0.765^{* * *}$ & 0.123 & 6.234 \\
\hline
\end{tabular}

Note: ${ }^{* * *} p<0.001$; QWL $=$ quality of work-life

\section{Moderating Effects of Organisational Ownership Structure}

The multigroup analysis found that there are significant differences in how employees in the state-owned enterprises and private-owned enterprises employed their psychological capital to deal with burnout and quality of work-life. The first step in multigroup analysis with SEM is to compare the ability to explain the data by the constrained model (the coefficients for paths are constrained to be equal between groups) and unconstrained one (the coefficients for paths can be different between groups). As a result, the constrained and unconstrained models show significantly different fit for the data in the sample $\left(\triangle \chi^{2}=8.547, \triangle \mathrm{df}=3\right.$, $p=0.036)$. Then, the analysis proceeded to the path by path analysis to examine if which particular path coefficients are statistically different between groups. It was found that there are significantly different at the path of psychological capital to burnout $\left(\triangle \chi^{2}=6.377, \triangle \mathrm{df}=1, p=0.011\right)$ and the path of psychological capital to quality of work-life $\left(\triangle \chi^{2}=5.467, \triangle \mathrm{df}=1, p=0.02\right)$.

As indicated in Table 4, in private-owned companies, psychological capital shows significant impacts on burnout $(\beta=-0.465, p<0.001)$; however, in the state-owned companies, the relationship is insignificant $(\beta=-0.134, p=0.176)$. 
Though the psychological capital still presents the negative linear direct effects to burnout, it is suggested that psychological capital might not be a strong and significant remedy for the employees' burnout in public enterprises. For the path of psychological capital to quality of work-life, there are significant differences in coefficient value across two types of organisation ( $\beta=0.573$ vs. $\beta=0.787$ ) though both are statistically significant. It means that the impact of psychological capital on the quality of work-life is much more prevalent in the working environment of state-owned enterprises. Thus, both hypotheses $\mathrm{H} 4 \mathrm{a}$ and $\mathrm{H} 4 \mathrm{~b}$ were supported.

Table 4

Moderating effects of organisational ownership structure

\begin{tabular}{llclc}
\hline \multirow{2}{*}{ Structural path } & \multicolumn{2}{c}{ Private-owned enterprises } & \multicolumn{2}{c}{ State-owned enterprises } \\
\cline { 2 - 5 } & Estimate & $t$-stat & Estimate & $t$-stat \\
\hline Psychological capital $\rightarrow$ Burnout & $-0.465^{* *}$ & -3.071 & -0.134 & -1.345 \\
Burnout $\rightarrow$ QWL & $-0.245^{* * *}$ & -3.621 & $-0.201^{* * *}$ & -3.576 \\
Psychological capital $\rightarrow$ QWL & $0.573^{* *}$ & 6.073 & $0.787^{* * *}$ & 5.984 \\
\hline Note: ${ }^{* *} p<0.05 ;{ }^{* * *} p<0.001$ & & &
\end{tabular}

\section{Moderating Effects of Demographic Characteristics}

The multigroup analysis in SEM procedures described above was also employed to test the moderating effects of employee demographic characteristics (age and gender) on the relationship among psychological capital, quality of work-life, and burnout. It is noted that there were two groups for each moderating variable, i.e., age (younger and older) and gender (female and male). The results of the multigroup analysis revealed that no difference was found in the two models (unconstrained and constrained) in terms of gender of employees (female and male) $\left(\triangle \chi^{2}=\right.$ 3.468, $\triangle \mathrm{df}=3, p=0.325$ ) and in terms of age of employees (younger and older) $\left(\triangle \chi^{2}=5.153, \triangle \mathrm{df}=3, p=0.16\right)$. Therefore, we can conclude that the employee demographic characteristics did not affect the relationship between psychological capital, quality of work-life, and burnout. Hence, hypotheses H5a and H5b were not supported. 


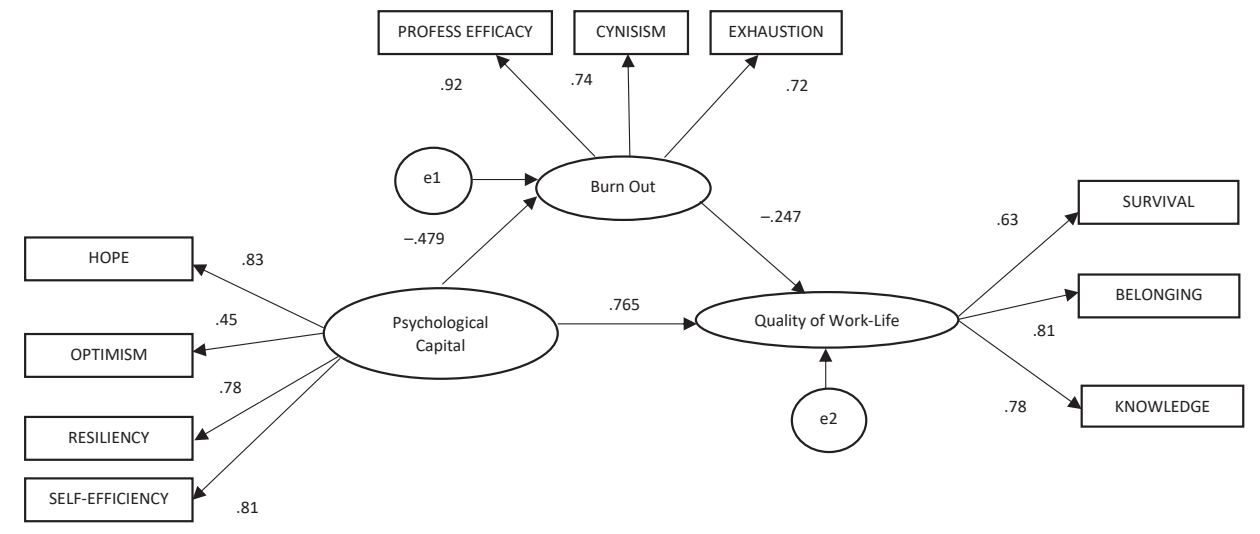

Figure 2. Structural results

\section{DISCUSSION}

Quality of work-life is proven to be tremendously substantial and affects different aspects of employees and organisations (Efraty et al., 1991). Thus, enhancing the level of quality of work-life among employees has been one of the most desired and useful tools for creating the mutual benefit of both employees and employers across industries. This study contributed to the research on the topic by considering the effects of psychology capital and burnout on the quality of work-life of Vietnamese employees. Specifically, the SEM results, based on a data set collected from 302 employees, disclosed that psychological capital was negatively associated with burnout. This outcome was not only parallel with the proposed hypotheses but also consistent with the existing literature of Ding et al. (2015). Employees who have higher hope, self-efficacy, resilience, and optimism characteristics are less likely to encounter the symptoms of burnout. More importantly, psychological capital can effectively influence burnout process which was developed step by step through three stages from exhaustion to depersonalisation to lack of efficacy. Thus, employees and organisations themselves can detect and treat the syndromes of burnout promptly by enhancing psychological capital. Another finding in this study, akin to results from previous researches (Nguyen \& Nguyen, 2012; Nguyen et al., 2014), found that psychological capital was positively related to the quality of work-life. However, prior studies concentrated only on one type of employee such as marketing staff or in one business sector mostly in the healthcare industry, whilst the sample of this study included diverse specialisation and position level of employees which bring broader context to the finding and make the finding more generalised. These results contributed to add burnout and quality of work-life into the research stream of psychological capital's outcomes, clearly 
providing the influence and importance of psychological capital in management and organisational behaviour. Also, this study confirmed the negative relationship between burnout and quality of work-life. Quality of work-life can be boosted by reducing burnout of individuals.

Organisational context (state-owned or private-owned), as predicted, moderated relationships of psychological capital with burnout and quality of work-life. The findings in Table 4 showed that the effects of psychological capital on quality of work-life are stronger in state-owned enterprises than their peers in privateowned sectors ( $\beta=0.787$ vs. $\beta=0.573$ ). This indicated that the environments of state-owned enterprises is easier to achieve a higher quality of work-life given the same psychological capital of the employees. This is contrary to the outcomes of previous research of Lyons et al. (2006) and Shahnawaz and Jafri (2009) that organisational characteristics have limited impacts on psychological capital and private employees seem to have higher psychological capital than public ones. Negative effects of psychological capital on the burnout are much lesser in the environment of state-owned enterprises ( $\beta=-0.465$ vs. $\beta=-0.134)$. This outcome is in line with the national study of Yeh et al. (2018) and contradicts Ferreira and Martinez's (2012). Arguably, it is the differences in the working environment between two types of enterprises that can create different criteria for achieving the quality of work-life. Public enterprises' employees are normally those who are looking for job stability, reasonable salary, and the satisfaction of basic human needs (Markovits et al., 2010). Clark and Senik (2006) revealed that the remarkable difference between the two types of enterprises was job security which were based on two reasons. First, the possibility of losing jobs is rare because employees usually legally protected by long-term contracts except for the case if they are committed crime. Second, it is easier for the case of bankruptcy in private sectors compared to public ones. Therefore, they can easily achieve the quality of work-life compared to those working in private organisations where the working environment needs more creation and pressure. In contrast, employees hardly find such security in the private sector. They also often have to work more hours in a higher competitive environment in order to retain their current jobs and positions. The relationship between psychological capital and burnout is thus more influenced by the private-owned organisation's context.

Findings in the multigroup analysis in Table 4 indicated that employee demographic characteristics did not alter the relationships among psychological capital, quality of work-life, and burnout. These findings interestingly disagreed with those found in Bonanno (2004) that men are more resilient. Also, these findings contradicted the claim that women may tend to be more emotionally exhausted than men, but men tend to be more depersonalised than women (Purvanova \& Muros, 2010). 
The explanations for these disagreements might lie in the cultural-specific and economic-specific reasons. In developing economies like Vietnam where the income level of people is still much lower comparing to developed countries, people are not keen to express their distinct individual characteristics (inherited from gender or age differences) into working environments. It is more likely that people tend to put aside their individual needs to strive for the fulfillment of the assigned tasks. Employees in Asian countries like Vietnam also tend to follow the instructions from their supervisors and managers voluntarily. Thus, demographic characteristics did not play the moderating effects on the relationships between psychological capital, quality of work-life, and burnout.

Notably, the analysis in this study highlighted the mediating effects of burnout in the relationship between psychological capital and quality of work-life in general. However, the burnout performs only partial mediating effects when the direct effect of psychological capital on quality of work-life is still significant $(\beta=0.765$, $t$-stat $=6.234$ ). Additionally, results in the multigroup analysis in Table 4 showed that the burnout only performs mediating effects in the private-owned enterprise context. This finding suggests that managers in private companies could consider paying more attention to exploit employees' available psychological capital for directly reducing their burnout, which in turn could result in a better employee's quality of work-life.

\section{CONCLUSION}

In terms of theoretical perspectives, the role of psychological capital is highlighted in this study. It might be that increasing employees' psychological capital is a sufficient strategy for enhancing the employees' quality of work-life and reducing job burnout. Companies should include psychological capital in their recruitment plan to increase the probability of hiring personnel with a high level of psychological capital. Based on the results of this study, it is confirmed that appropriate strategies and personnel policies should be implemented in organisations through enhancing HERO (hope, efficacy, resilience, and optimism) of employees. For instance, Luthans and Youssef (2017) proposed an intervention model named psychological capital intervention (PCI) to increase and replenish HERO by various tools including SMART (specific, measurable, achievable, realistic, and timely) goal setting; writing positive actions, grateful things and grateful letters frequently, keeping balance in daily life through exercises, relationships, yoga and meditation, and proper eating habits. These activities can be implemented by different flexible methods such as traditional face-to-face and online coaching or by applications, smartphone games, and gamification methods. 
In this study, the contexts of the working environment are proved to be extremely crucial for a successful psychological development intervention plan. The finding of moderating roles of organisational ownership structures complement the research stream of psychological capital's outcomes. These results are also compatible with Luthans and Youssef (2017) suggestion that the connections between psychological capital and its outcomes might not be linear but affected by mediators and moderators: for example, organisational ownership structure in this study. When boosting employees' psychological capital, private-owned companies can reduce burnout more effectively rather than the state-owned companies. However, state-owned companies can increase employees' quality of work-life more easily and significantly, given the same level of employees' psychological capital. These results help managers to be proactive in personnel management strategies of companies in specific contexts. Beside reducing burnout through the effects of psychological capital, other factors such as workload, control, reward, community, fairness, and values (Schaufeli et al., 2002) also need to be noticed to gain quality of work-life of their employees, which is a critical factor for productivity (Wright \& Cropanzano, 2004).

This study also had some limitations. Firstly, although the number of observations in the sample is not small compared to other standardised own-funding research, it is advised to use much bigger samples to increase the generalisation of the findings. Second, the model in this study needs further replication, extension, and critical evaluation in other different contexts such as developing nations vs. developed nations to provide useful insights on how the working environment or cross-culture contexts might affect the employees' psychology and behaviours. Third, this study did not include the effects of employees' job characteristics on their well-being and psychology. Thus, examining the model with different employee positions and tasks within organisations such as human resources, sales, marketing, and comparing the results can substantially provide much more extended insights on the interrelationships between psychological capital, quality of work-life, and burnout. Only the individual level of psychological capital was studied in this paper. Analysing higher levels of psychological capital in a group/ team or organisation is also a proper direction for future research. Lastly, the research of Canadian Mental Health Association (2019) have suggested further investigation of this model to overcome burnout among entrepreneurs. 


\section{REFERENCES}

Akar, H. (2018). The relationships between quality of work life, school alienation, burnout, affective commitment and organizational citizenship: A study on teachers. European Journal of Educational Research, 7(2), 169-181. https://doi. org/10.12973/eu-jer.7.2.169

Anagnostopoulos, F., \& Niakas, D. (2010). Job burnout, health-related quality of life, and sickness absence in Greek health professionals. European Psychologist, 15, 132-141https://doi.org/10.1027/1016-9040/a000013

Arandjelovic, M., Nikolic, M., \& Stamenkovic, S. (2010). Relationship between burnout, quality of life, and work ability index: Directions in prevention. The Scientific World Journal, 10, 766-777. https://doi.org/10.1100/tsw.2010.83

Avey, J. B., Nimnicht, J. L., \& Graber Pigeon, N. (2010). Two field studies examining the association between positive psychological capital and employee performance. Leadership \& Organization Development Journal, 31(5), 384-401. https://doi. org/10.1108/01437731011056425

Avey, J. B., Reichard, R. J., Luthans, F., \& Mhatre, K. H. (2011). Meta-analysis of the impact of positive psychological capital on employee attitudes, behaviors, and performance. Human Resource Development Quarterly, 22(2), 127-152. https:// doi.org/10.1002/hrdq.20070

Block, J., \& Kremen, A. M. (1996). IQ and ego-resiliency: Conceptual and empirical connections and separateness. Journal of Personality and Social Psychology, 70(2), 349-361. https://doi.org/10.1037/0022-3514.70.2.349

Bodewig, C., Badiani-Magnusson, R., Macdonald, K., Newhouse, D., \& Rutkowski, J. (2014). Skilling up Vietnam: Preparing the workforce for a modern market economy. In Directions in development: Human development. Washington, DC: World Bank. https://doi.org/10.1596/978-1-4648-0231-7

Bonanno, G. A. (2004). Loss, trauma, and human resilience: Have we underestimated the human capacity to thrive after extremely aversive events. American Psychologist, 59(1), 20-28. https://doi.org/10.1037/0003-066X.59.1.20

Canadian Mental Health Association. (2019). Going it alone: The mental health and wellbeing of Canada's entrepreneurs. Retrieved 10 September 2020 from https:// cmha.ca/wp-content/uploads/2019/06/GoingitAlone-CMHA-BDCReportFINAL-EN.pdf

Carver, C. S., \& Scheier, M. F. (2002). Optimism. In C. R. Snyder, \& S. J. Lopez (Eds.), Handbook of positive psychology, 231-243. Oxford, UK: Oxford University Press.

Clark, A. E., \& Senik, C. (2006). The (unexpected) structure of "rents" on the French and British labour markets. The Journal of Socio-Economics, 35(2), 180-196. https:// doi.org/10.1016/j.socec.2005.11.010

Dello Russo, S., \& Stoykova, P. (2015). Psychological capital intervention (PCI): A replication and extension. Human Resource Development Quarterly, 26(3), 329347. https://doi.org/10.1002/hrdq.21212 
Demerouti, E., van Eeuwijk, E., Snelder, M., \& Wild, U. (2011). Assessing the effects of a "personal effectiveness" training on psychological capital, assertiveness and selfawareness using self-other agreement. Career Development International, 16(1). https://doi.org/10.1108/13620431111107810

Ding, Y., Yang, Y., Yang, X., Zhang, T., Qiu, X., He, X., Wang, W., Wang, L., \& Sui, H. (2015). The mediating role of coping style in the relationship between psychological capital and burnout among Chinese nurses. PloS One, 10(4). https://doi.org/10.1371/journal.pone.0122128

Donaldson, S. I., \& Ko, I. (2010). Positive organizational psychology, behavior, and scholarship: A review of the emerging literature and evidence base. The Journal of Positive Psychology, 5(3), 177-191. https://doi.org/10.1080/17439761003790930

Efraty, D., Sirgy, M. J., \& Claiborne, C. B. (1991). The effects of personal alienation on organizational identification: A quality-of-work-life model. Journal of Business and Psychology, 6(1), 57-78. https://doi.org/10.1007/BF01013685

Ferreira, A. I., \& Martinez, L. F. (2012). Presenteeism and burnout among teachers in public and private Portuguese elementary schools. The International Journal of Human Resource Management, 23(20), 4380-4390. https://doi.org/10.1080/095 85192.2012.667435

Fornell, C., \& Larcker, D. F. (1981). Evaluating structural equation models with unobservable variables and measurement error. Journal of Marketing Research, 18(1), 39-50. https://doi.org/10.1177/002224378101800104

Gupta, M., Shaheen, M., \& Das, M. (2019). Engaging employees for quality of life: Mediation by psychological capital. The Service Industries Journal, 39(5-6), 403-419. https://doi.org/10.1080/02642069.2018.1462799

Judge, T. A., Jackson, C. L., Shaw, J. C., Scott, B. A., \& Rich, B. L. (2007). Self-efficacy and work-related performance: The integral role of individual differences. Journal of Applied Psychology, 92(1), 107-127. https://doi.org/10.1037/00219010.92.1.107

Karisalmi, P. T. S. (1999). Impact of working life quality on burnout. Experimental Aging Research, 25(4), 441-449. https://doi.org/10.1080/036107399243922

Luo, H., \& Hao, Z. H. (2010). The relationships among psychological capital, job burnout and turnover intention in 466 nurses. Chinese Journal of Nursing, 45(10), 933935.

Luthans, F. (2002). The need for and meaning of positive organizational behavior. Journal of Organizational Behavior, 23(6), 695-706. https://doi.org/10.1002/job.165

Luthans, F., Avolio, B. J., Walumbwa, F. O., \& Li, W. (2005). The psychological capital of Chinese workers: Exploring the relationship with performance. Management and Organization Review, 1(2), 249-271. https://doi.org/10.1111/j.17408784.2005.00011.x

Luthans, F., Luthans, K. W., \& Luthans, B. C. (2004). Positive psychological capital: Beyond human and social capital. Business Horizons, 47(1), 45-50. https://doi. org/10.1016/j.bushor.2003.11.007

Luthans, F., Youssef, C. M., \& Avolio, B. J. (2007). Psychological capital: Developing the human competitive edge. Oxford: Oxford University Press. 
Luthans, F, Youssef-Morgan, C. M., Avolio, B. (2015). Psychological capital and beyond. New York: Oxford University Press.

Luthans, F., \& Youssef-Morgan, C. M. (2017). Psychological capital: An evidencebased positive approach. Annual Review of Organizational Psychology and Organizational Behavior, 4(1), 339-366. https://doi.org/10.1146/annurevorgpsych-032516-113324

Lyons, S. T., Duxbury, L. E., \& Higgins, C. A. (2006). A comparison of the values and commitment of private sector, public sector, and parapublic sector employees. Public Administration Review, 66(4), 605-618. https://doi.org/10.1111/j.15406210.2006.00620.x

Markovits, Y., Davis, A. J., Fay, D., \& Dick, R. V. (2010). The link between job satisfaction and organizational commitment: Differences between public and private sector employees International Public Management Journal, 13(2), 177-196. https:// doi.org/10.1080/10967491003756682

Marta, J. K. M., Singhapakdi, A., Lee, D., Sirgy, M. J., Koonmee, K., \& Virakul, B. (2013). Perceptions about ethics institutionalization and quality of work life: Thai versus American marketing managers. Journal of Business Research, 66(3), 381. https:// doi.org/10.1016/j.jbusres.2011.08.019

Maslach, C. (2003). Job burnout new directions in research and intervention. Current Directions in Psychological Science, 12(5), 189-192. https://doi. org/10.1111/1467-8721.01258

Maslach, C., Jackson, S. E., \& Leiter, M. P. (1996). Maslach burnout inventory manual (3rd ed.). Palo Alto, CA: Consulting Psychologists Press.

Maslach, C., Schaufeli, W. B., \& Leiter, M. P. (2001). Job burnout. Annual Review of Psychology, 52(1), 397-422. https://doi.org/10.1146/annurev.psych.52.1.397

Newman, A., Ucbasaran, D., Zhu, F. E. I., \& Hirst, G. (2014). Psychological capital: A review and synthesis. Journal of Organizational Behavior, 35(S1), S120-S138. https://doi.org/10.1002/job.1916

Nguyen, T. D., \& Nguyen, T. T. M. (2012). Psychological capital, quality of work life, and quality of life of marketers: Evidence from Vietnam. Journal of Macromarketing, 32(1), 87-95 https://doi.org/10.1177/0276146711422065

Nguyen, D. T., Nguyen, D. P., \& Minh, T. H. (2014). Marketers' psychological capital and performance. Asia-Pacific Journal of Business Administration, 6(1), 36-48 https://doi.org/10.1108/APJBA-04-2013-0026

Parker, S. K. (1998). Enhancing role breadth self-efficacy: The roles of job enrichment and other organizational interventions. Journal of Applied Psychology, 83(6), 835-852. https://doi.org/10.1037/0021-9010.83.6.835

Peterson, S. J., Luthans, F., Avolio, B. J., Walumbwa, F. O., \& Zhang, Z. (2011). Psychological capital and employee performance: A latent growth modeling approach. Personnel Psychology, 64(2), 427-450. https://doi.org/10.1111/j.17446570.2011.01215.x

Podsakoff, P. M., MacKenzie, S. B., Lee, J. Y., \& Podsakoff, N. P. (2003). Common method biases in behavioral research: A critical review of the literature and recommended remedies. Journal of Applied Psychology, 88(5), 879-903. https:// doi.org/10.1037/0021-9010.88.5.879 
Pretty, G. M., McCarthy, M. E., \& Catano, V. M. (1992). Psychological environments and burnout: Gender considerations within the corporation. Journal of Organizational Behavior, 13(7), 701-711. https://doi.org/10.1002/job.4030130706

Pu, J., Hou, H., Ma, R., \& Sang, J. (2017). The effect of psychological capital between work-family conflict and job burnout in Chinese university teachers: Testing for mediation and moderation. Journal of Health Psychology, 22(14), 1799-1807. https://doi.org/10.1177/1359105316636950

Purvanova, R. K., \& Muros, J. P. (2010). Gender differences in burnout: A meta-analysis. Journal of Vocational Behavior, 77(2), 168-185. https://doi.org/10.1016/j. jvb.2010.04.006

Schaufeli, W. B., Salanova, M., González-Romá, V., \& Bakker, A. B. (2002). The measurement of engagement and burnout: A two sample confirmatory factor analytic approach. Journal of Happiness Studies, 3(1), 71-92. https://doi. org/10.1023/A:1015630930326

Schutte, N., Toppinen, S., Kalimo, R., \& Schaufeli, W. (2000). The factorial validity of the Maslach Burnout Inventory-General Survey (MBI-GS) across occupational groups and nations. Journal of Occupational and Organizational Psychology, 73(1), 53-66. https://doi.org/10.1348/096317900166877

Seligman, M. E., Steen, T. A., Park, N., \& Peterson, C. (2005). Positive psychology progress: Empirical validation of interventions. American Psychologist, 60(5), 410. https://doi.org/10.1037/0003-066X.60.5.410

Shahnawaz, M. G., \& Jafri, M. H. (2009). Psychological capital as predictors of organizational commitment and organizational citizenship behaviour Journal of the Indian Academy of Applied Psychology 35(Special Issue), 78-84.

Sirgy, M. J., Efraty, D., Siegel, P., \& Lee, D. J. (2001). A new measure of staff quality of work life (QWL) based on need satisfaction and spillover theories. Social Indicators Research, 55(3), 241-302. https://doi.org/10.1023/A:1010986923468

Snyder, C. R., Irving, L. M., \& Anderson, J. R. (1991). Hope and health. Handbook of Social and Clinical Psychology: The Health Perspective, 162, 285-305.

Snyder, C. R., Rand, K. L., \& Sigmon, D. R. (2002). Hope theory. Handbook of Positive Psychology, 257-276.

Stajkovic, A. D., \& Luthans, F. (1998). Self-efficacy and work-related performance: A meta-analysis. Psychological Bulletin, 124(2), 240. https://doi.org/10.1037/00332909.124.2.240

Steenkamp, J. B. E., \& Van Trijp, H. C. (1991). The use of LISREL in validating marketing constructs. International Journal of Research in Marketing, 8(4), 283-299. https://doi.org/10.1016/0167-8116(91)90027-5

Vietnam General Statistics Office. (2019). Statistical yearbook of Vietnam 2018. Retrieved 15 September 2020 from https://www.gso.gov.vn/en/data-andstatistics/2019/10/statistical-yearbook-of-vietnam-2018/

Wright, T. A., \& Cropanzano, R. (2004). The role of psychological well-being in job performance: A fresh look at an age-old quest. Organizational Dynamics, 33(4), 338-351. https://doi.org/10.1016/j.orgdyn.2004.09.002 
Yeh, W. Y., Yeh, C. Y., \& Chen, C. J. (2018). Exploring the public-private and company size differences in employees' work characteristics and burnout: Data analysis of a nationwide survey in Taiwan. Industrial Health, 56(5), 452-463. https://doi. org/10.2486/indhealth.2017-0182

Youssef, C. M., \& Luthans, F. (2007). Positive organizational behavior in the workplace the impact of hope, optimism, and resilience. Journal of Management, 33(5), 774-800. https://doi.org/10.1177/0149206307305562 